Review

\title{
Social Life Cycle Assessment Revisited
}

\section{Ruqun Wu ${ }^{1}{ }^{*}$, Dan Yang ${ }^{2}$ and Jiquan Chen ${ }^{1}$}

1 Centre for Global Change \& Earth Observations, Department of Geography, Michigan State University, East Lansing, MI 48823, USA; E-Mail: Jqchen@msu.edu

2 British Standard Institute, Great China Region, Room 2008, East Ocean Center, No. 24A, Jianguomenwai Street, Beijing 100004, China; E-Mail: Diana.yang@bsigroup.com

* Author to whom correspondence should be addressed; E-Mail: ruqunvi@hotmail.com; Tel.: +1-567-225-2086; Fax: +1-517-432-1671.

Received: 1 March 2014; in revised form: 17 June 2014 / Accepted: 18 June 2014 / Published: 2 July 2014

\begin{abstract}
To promote the development of Social Life Cycle Assessment (SLCA), we conducted a comprehensive review of recently developed frameworks, methods, and characterization models for impact assessment for future method developers and SLCA practitioners. Two previous reviews served as our foundations for this review. We updated the review by including a comprehensive list of recently-developed SLCA frameworks, methods and characterization models. While a brief discussion from goal, data, and indicator perspectives is provided in Sections 2 to 4 for different frameworks/methods, the focus of this review is Section 5 where discussion on characterization models for impact assessment of different methods is provided. The characterization models are categorized into two types following the UNEP/SETAC guidelines: type I models without impact pathways and type II models with impact pathways. Different from methods incorporating type I/II characterization models, another LCA modeling approach, Life Cycle Attribute Assessment (LCAA), is also discussed in this review. We concluded that methods incorporating either type I or type II models have limitations. For type I models, the challenge lies in the systematic identification of relevant stakeholders and materiality issues; while for type II models, identification of impact pathways that most closely and accurately represent the real-world causal relationships is the key. LCAA may avoid these problems, but the ultimate questions differ from those asked by the methods using type I and II models.
\end{abstract}


Keywords: SLCA; review; social life cycle impact assessment; UNEP/SETAC guidelines

\section{Introduction}

The discussion of integrating social aspects into Life Cycle Assessment (LCA) started in the 1990s [1], and the comprehensive overview of the history of Social Life Cycle Assessment (SLCA) development and the definition of SLCA can be found in Benoit et al. [2]. Reviews on SLCA include seminar/conference proceedings [3,4] and review of the guidelines for the SLCA of products by the United Nations Environment Programme (UNEP) and the Society of Environmental Toxicology and Chemistry (SETAC) Life Cycle Initiative (hereafter the UNEP/SETAC guidelines) [2]. Two thorough reviews on SLCA were provided by Jørgensen et al. [5] and Parent et al. [6]. However, since the publication of the UNEP/SETAC guidelines [2,7], new SLCA frameworks/methods have been developing at an increasing rate. There is an urgent need in updating the methodology development for LCA practitioners.

The core of the UNEP/SETAC guidelines is its fourth chapter, where the guideline for performing a SLCA is presented [7]. Taking a bottom up view, the inventory data in SLCA are collected to compute the inventory indicators that can be aggregated/linked into subcategories that will be further aggregated/linked into impact categories and/or stakeholder categories [7]. The approaches for the aggregation for each type of impact categories (and thus characterization models) are to be selected during the impact assessment stage. As identified in the guidelines, type I impact categories aggregate the results for the subcategories within a theme of interest to a stakeholder [7]; thus, the characterization model is to simply aggregate inventory indicators into (sub)impact categories. Whereas, type II impact categories model the results for the subcategories that have a causal relationships defined in the criteria (e.g., autonomy) [7]. The characterization model is used to link inventory indicators to (sub)impact categories through causal relationships (i.e., the impact pathways). The detailed discussion on type I and type II characterization models is provided in Section 5, together with Life Cycle Attribute Assessment (LCAA) as a different method for measuring certain attributes of a product along its life cycle.

In this paper, "frameworks" refers to studies that provide theoretical frameworks. "Methods" refers to detailed SLCA methods (with indicators, (sub)impact categories identified, and characterization models developed). "Models" refers to the characterization models (according to type I or type II impact categories) during Social Life Cycle Impact Assessment (SLCIA) (Figure 1). The categorization to "frameworks" or "methods" is illustrated under "type of approach" (Figure 2). The relationships between the frameworks, methods, and characterization models indicate that the general frameworks may or may not lead to detailed methods development, where each method (except for LCAA) has its own characterization models (i.e., type I or type II impact categories). Although it was included in Section 5 with a discussion on type I/II characterization models, LCAA is not an impact assessment method itself; rather, it is a new LCA method/modeling approach and should not be considered as parallel to type I/II characterization modeling. 
Figure 1. Conceptual illustration of the relationships among SLCA frameworks, methods and characterization models.

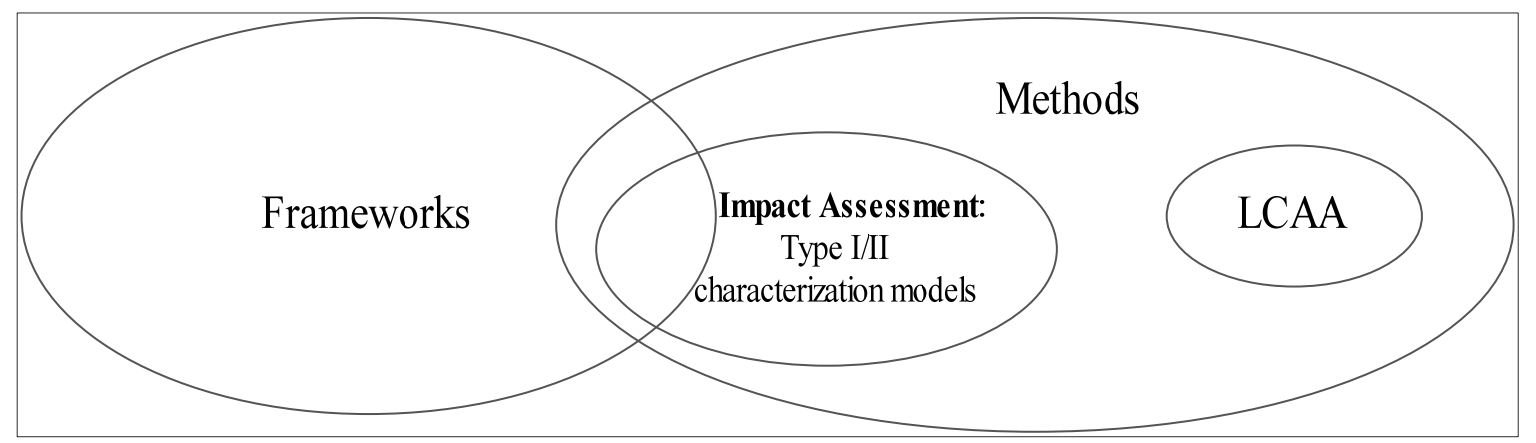

Note: A method may be independently developed from a framework or can be developed as an extension of a framework. A method can incorporate type I/II characterization modeling for SLCIA. LCAA is a new modeling approach without using type I/II characterization models.

The focus of this review is Section 5 with discussions on type I/II characterization models for impact assessment of different methods and discussions on LCAA. Before Section 5, general overviews of different frameworks and methods are provided regarding their overall goals, type of approach, social issues coverage (Section 2), data levels and collection (Section 3), as well as indicators types and data attributes of indicators (Section 4) (Figure 2). Due to the nature of this review, the discussion elements are mingled into these (results) Sections and are further discussed in Section 6.

All of the frameworks, methods, and characterization models reviewed here are published in journal papers. We focused on reviewing the recently-developed methods (e.g., frameworks/methods developed after the publication of the UNEP/SETAC guidelines; Table A1). However, several significant publications on frameworks and methods are retained in this review to assure a systematic review. 
Figure 2. Overview of different frameworks and methods regarding their overall goal, type of approach, coverage of social issues, data level and collection, indicator type, and the data attributes of the indicator [8-33].

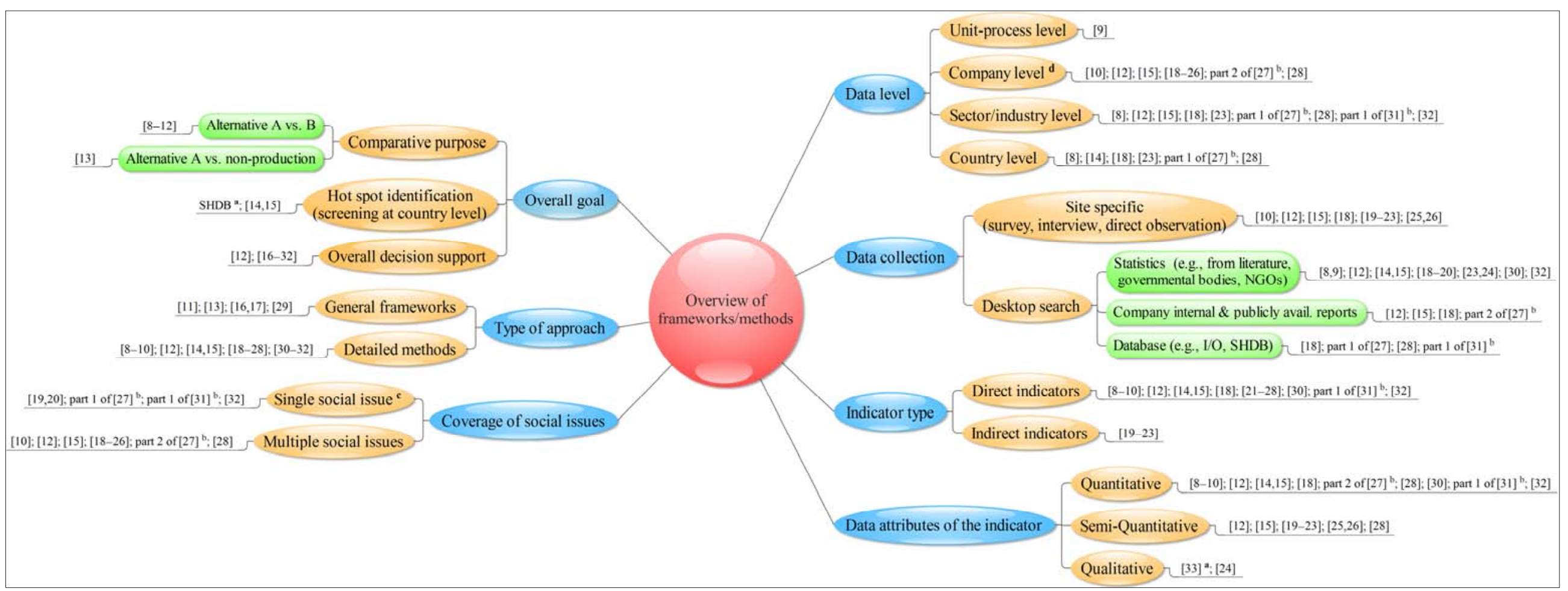

Notes: The relative frameworks/methods were numbered in the Figure according to their numbers in the references, for example, the left-right number "19" refers to the method proposed by Hunkeler [9]. ${ }^{a}$ The Social Hotspot Database (SHDB) and Gauthier [33] were not reviewed in detail in this paper; ${ }^{b}$ The part 1/part 2 of [27] and [31] was explained in Table A1; ${ }^{\mathrm{c}}$ The "single social issue" here means coverage at only one stakeholder level (e.g., workers); ${ }^{\mathrm{d}}$ The company level data may or may not be obtained from first-hand data, as elaborated in the data collection section. It could be from first-hand data through survey, interview, or a second-hand data source through company reports. 


\section{Overall Goals, Type of Approach, and Coverage of Social Issues}

For practitioners, the first question being asked prior to applying/adopting a method is whether the overall goal, the type of approach, and the coverage of social issues would fit their studied system. Similarly for SLCA developers, an overview of available frameworks/methods is necessary before developing a framework and associated method.

As pointed out in the UNEP/SETAC guidelines [7] and Jørgensen [34], SLCA is a methodology for decision support for the social impacts related to product life cycles. While most of the SLCA frameworks/methods are goal-oriented, some have pre-determined goals (e.g., hot-spot identification, comparative and/or non-comparative purposes; Figure 2). For frameworks/methods developed for comparative studies, more than two alternative products are typically included. The consequential SLCA proposed by Jørgensen et al. [13] is designed for comparative studies, but it specifically compares a product chain with "no chain" (non-production). Another consequential SLCA developed by Lagarde and Macombe [11] compared two alternative production choices. The SHDB and its related studies $[14,35,36]$ were designed particularly for high-level product category assessment and screening the social hot-spots from the sector and country level, instead of a particular product chain.

Regarding the type of approach of reviewed SLCA frameworks/methods, some are general frameworks, which may provide thoughts for future method developers instead of targeting practitioners. Others are detailed SLCA methods and often accompanied by case studies to demonstrate their methods (Figure 2). When considering the type of approach, it is also practically important to group each framework/method according to the coverage of the social issues. For example, it may not be sufficient for a company to make a decision depending on a single criterion. We categorized a framework/method as either covering a single social issue or multiple social issues (Figure 2).

The previous review, by Jørgensen et al. [5], categorized each method according to the impact categories of the Global Reporting Initiative (GRI). With the availability of the UNEP/SETAC guidelines, the grouping can be made according to the guidelines (i.e., five stakeholder categories and breakdown of the subcategories; Table 1). We identified the coverage of the social issues at the indicator levels for the selected methods. For the frameworks, though some elaborated specific social criteria (e.g., the framework proposed by Reitinger et al. [16] can virtually include all of the social criteria identified in the guidelines. The framework proposed by Dreyer et al. [17] covers worker related issues), most of the frameworks are not probed in details due to the generality of the frameworks and, hence, are not specified in Table 1. Most of the methods emphasize the stakeholder of workers, with some covering more criteria for workers than those recommended by the UNEP/SETAC guidelines. In contrast, the stakeholders of consumer and value chain actors are rarely considered. 
Table 1. Coverage of social issues at indicator level of methods incorporating type I characterization models ${ }^{1}$ according to the UNEP/SETAC guidelines.

\begin{tabular}{|c|c|c|c|c|c|c|c|c|c|c|c|c|}
\hline $\begin{array}{l}\text { Stakeholder } \\
\text { categories }\end{array}$ & Subcategories & $\begin{array}{l}\text { Schmidt et al. } \\
\qquad 2005\end{array}$ & $\begin{array}{c}\text { Hutchins } \\
\text { and } \\
\text { Sutherland } \\
2^{2008}{ }^{2} \\
\end{array}$ & $\begin{array}{c}\text { Dreyer } \\
\text { et al. } 2^{2010}{ }^{2}\end{array}$ & $\begin{array}{l}\text { Ciroth } \\
\text { and } \\
\text { Franze } \\
2011 \\
\end{array}$ & $\begin{array}{c}\text { Aparcana } \\
\text { and } \\
\text { Salhofer } \\
2013 \\
\end{array}$ & $\begin{array}{c}\text { Foolmaun } \\
\text { and } \\
\text { Ramjeeawon } \\
2013\end{array}$ & $\begin{array}{l}\text { Hsu } \\
\text { et al. } \\
2013\end{array}$ & $\begin{array}{l}\text { Hosseinijou } \\
\text { et al. } 2013^{3}\end{array}$ & $\begin{array}{c}\text { Manik } \\
\text { et al. } \\
2013\end{array}$ & $\begin{array}{l}\text { Vinyes } \\
\text { et al. } \\
2013^{4}\end{array}$ & $\begin{array}{c}\text { Martínez-Blanco } \\
\text { et al. } 2014^{5}\end{array}$ \\
\hline \multirow{8}{*}{ Workers ${ }^{6}$} & $\begin{array}{l}\text { Freedom of } \\
\text { association, collective } \\
\text { bargaining }\end{array}$ & $\times$ & & $x$ & $\times$ & $x$ & & $\times$ & $x$ & $x$ & & $x$ \\
\hline & Child labor & $x$ & & $x$ & $x$ & $x$ & $\times$ & $x$ & $\times$ & & & $x$ \\
\hline & Fair salary & $\times$ & $\times$ & & $x$ & $\times$ & $\times$ & $x$ & $\times$ & $x$ & & $\times$ \\
\hline & Working hours & & & & $x$ & $x$ & & $x$ & & $x$ & $x$ & $x$ \\
\hline & Forced labor & $x$ & & $x$ & $\times$ & & $\times$ & $x$ & $\times$ & $x$ & & $\times$ \\
\hline & $\begin{array}{l}\text { Equal opportunities/ } \\
\text { discrimination }\end{array}$ & $x$ & & $x$ & $x$ & $x$ & $x$ & $x$ & $x$ & $x$ & $x$ & $x$ \\
\hline & Health and safety & $x$ & $x$ & & $x$ & $x$ & $x$ & $x$ & $x$ & $x$ & & $x$ \\
\hline & $\begin{array}{l}\text { Social benefits/ } \\
\text { social security }\end{array}$ & $x$ & $\times$ & & $x$ & $\times$ & $x$ & $x$ & & $x$ & & \\
\hline \multirow[t]{2}{*}{ Workers ${ }^{6}$} & $\begin{array}{l}\text { Employees } \\
\text { development }\end{array}$ & $x$ & & & & & & & & & & \\
\hline & Families' benefits & $\times$ & $\times$ & & & $\times$ & & & & & $\times$ & \\
\hline \multirow{5}{*}{ Consumer } & Health and safety & $\times$ & & & $x$ & & & & & & & \\
\hline & Feedback mechanism & & & & $x$ & & & & & & & \\
\hline & Consumer privacy & & & & & & & & & & & \\
\hline & Transparency & $x$ & & & $\times$ & & & & & $x$ & & \\
\hline & $\begin{array}{l}\text { End of life } \\
\text { responsibility }\end{array}$ & & & & $x$ & & & & & & & \\
\hline
\end{tabular}


Table 1. Cont.

\begin{tabular}{|c|c|c|c|c|c|c|c|c|c|c|c|c|}
\hline $\begin{array}{l}\text { Stakeholder } \\
\text { categories }\end{array}$ & Subcategories & $\begin{array}{l}\text { Schmidt et al. } \\
\qquad 2005\end{array}$ & $\begin{array}{c}\text { Hutchins } \\
\text { and } \\
\text { Sutherland } \\
2008^{2} \\
\end{array}$ & $\begin{array}{c}\text { Dreyer } \\
\text { et al. } 2010^{2}\end{array}$ & $\begin{array}{c}\text { Ciroth } \\
\text { and } \\
\text { Franze } \\
2011 \\
\end{array}$ & $\begin{array}{c}\text { Aparcana } \\
\text { and } \\
\text { Salhofer } \\
2013 \\
\end{array}$ & $\begin{array}{c}\text { Foolmaun } \\
\text { and } \\
\text { Ramjeeawon } \\
2013 \\
\end{array}$ & $\begin{array}{l}\text { Hsu } \\
\text { et al. } \\
2013\end{array}$ & $\begin{array}{l}\text { Hosseinijou } \\
\text { et al. } 2013^{3}\end{array}$ & $\begin{array}{l}\text { Manik } \\
\text { et al. } \\
2013\end{array}$ & $\begin{array}{l}\text { Vinyes } \\
\text { et al. } \\
2013^{4}\end{array}$ & $\begin{array}{c}\text { Martínez-Blanco } \\
\text { et al. } 2014^{5}\end{array}$ \\
\hline \multirow{9}{*}{$\begin{array}{c}\text { Local } \\
\text { community }\end{array}$} & $\begin{array}{l}\text { Access to material } \\
\text { resources }\end{array}$ & & & & $\times$ & & & & $x$ & $\times$ & & $x$ \\
\hline & $\begin{array}{l}\text { Access to } \\
\text { immaterial resources }\end{array}$ & & & & $x$ & & & & & $x$ & & \\
\hline & $\begin{array}{l}\text { Delocalization and } \\
\text { migration }\end{array}$ & & & & $x$ & & & & & $\times$ & & \\
\hline & Cultural heritage & & & & $\times$ & & & & $x$ & $x$ & & \\
\hline & Safe and healthy & & & & $\times$ & & & & $\times$ & $\times$ & & $x$ \\
\hline & $\begin{array}{l}\text { living conditions } \\
\text { Respect of } \\
\text { indigenous rights }\end{array}$ & $x$ & & & $x$ & & & & & $x$ & & \\
\hline & Community engagement & $\times$ & & & $\times$ & & $\times$ & & & $\times$ & & \\
\hline & Local employment & $x$ & & & $\times$ & & & & $\times$ & $\times$ & $\times$ & \\
\hline & Secure living conditions & & & & $\times$ & & & & & $\times$ & & \\
\hline \multirow{5}{*}{ Society } & $\begin{array}{l}\text { Public commitments to } \\
\text { sustainability issues }\end{array}$ & $\times$ & $x$ & & $\times$ & & & & & $\times$ & $x$ & \\
\hline & $\begin{array}{l}\text { Contribution to } \\
\text { economic development }\end{array}$ & $x$ & & & $x$ & & $x$ & & $x$ & $x$ & $x$ & \\
\hline & $\begin{array}{l}\text { Prevention and mitigation } \\
\text { of armed conflicts }\end{array}$ & $x$ & & & $x$ & & & & & $x$ & & \\
\hline & Technology development & $\times$ & & & $\times$ & & & & $\times$ & $x$ & & \\
\hline & Corruption & $x$ & & & $x$ & & & & & $x$ & & $x$ \\
\hline
\end{tabular}


Table 1. Cont.

\begin{tabular}{|c|c|c|c|c|c|c|c|c|c|c|c|c|}
\hline $\begin{array}{l}\text { Stakeholder } \\
\text { categories }\end{array}$ & Subcategories & $\begin{array}{l}\text { Schmidt et al. } \\
\qquad 2005\end{array}$ & $\begin{array}{c}\text { Hutchins } \\
\text { and } \\
\text { Sutherland } \\
2^{2008}{ }^{2} \\
\end{array}$ & $\begin{array}{c}\text { Dreyer } \\
\text { et al. } 2010^{2}\end{array}$ & $\begin{array}{c}\text { Ciroth } \\
\text { and } \\
\text { Franze } \\
2011 \\
\end{array}$ & $\begin{array}{c}\text { Aparcana } \\
\text { and } \\
\text { Salhofer } \\
2013\end{array}$ & $\begin{array}{c}\text { Foolmaun } \\
\text { and } \\
\text { Ramjeeawon } \\
2013\end{array}$ & $\begin{array}{l}\text { Hsu } \\
\text { et al. } \\
2013\end{array}$ & $\begin{array}{l}\text { Hosseinijou } \\
\text { et al. } 2013^{3}\end{array}$ & $\begin{array}{c}\text { Manik } \\
\text { et al. } \\
2013\end{array}$ & $\begin{array}{l}\text { Vinyes } \\
\text { et al. } \\
2013^{4}\end{array}$ & $\begin{array}{c}\text { Martínez-Blanco } \\
\text { et al. } 2014^{5}\end{array}$ \\
\hline \multirow{4}{*}{$\begin{array}{l}\text { Value chain } \\
\quad(\text { excl. } \\
\text { Consumers }^{7} \text { ) }\end{array}$} & Fair competition & $x$ & & & $x$ & & & & $x$ & $\times$ & & \\
\hline & $\begin{array}{l}\text { Promoting social } \\
\text { responsibility }\end{array}$ & $x$ & & & $x$ & & & & & & & \\
\hline & Supplier relationships & & & & $x$ & & & & $\times$ & & & \\
\hline & $\begin{array}{l}\text { Respect of intellectual } \\
\text { property rights }\end{array}$ & & & & $x$ & & & & & & & \\
\hline
\end{tabular}

Notes: ${ }^{1}$ The names of the methods presented here can be found in Table A1. Section 5 provides discussions on type I/II characterization models. Frameworks and methods incorporating type II models are not presented. One method [14] incorporating type I models is not included because it is a country-level hot-spot identification. The method [24] (similar to [15]) is not presented. LCAA is not included because any types of "attributes" can be chosen for a single study; ${ }^{2}$ The coverage of social issues is categorized at indicator level, thus for Dreyer et al. [19,20], and Hutchins and Sutherland [27], they are categorized under "single social issues" in Figure 1 (at stakeholder level) but appear to cover four issues at indicator level in this Table; ${ }^{3}$ The ticked boxes are those selected for the case studies. For the method, all of the subcategories originally suggested by the UNEP/SETAC guidelines should be included. After the preliminary screening, only relevant and important subcategories are included in the follow-up site specific case studies; ${ }^{4}$ There are two other indicators considered: total employees with higher/basic education; however, we consider this as the background information, rather than social performance influenced by the conductance of the product systems; ${ }^{5}$ The method [28] differentiates the foreground/background processes at different scales (i.e., country, sector and company scale). Four groups of different indicators, subcategories, and stakeholders were identified for the foreground country/sector/company scale and the background sector scale, respectively. Issues covered under the foreground country scale were ticked as an example. For the foreground sector scale, except stakeholders/subcategories identified in the UNEP/SETAC guideline, a new stakeholder group "citizens collecting the organic fraction of the municipal solid waste" was identified with three new subcategories. Also, another new subcategory- "product application" was added under the stakeholder of "consumer"; ${ }^{6}$ The first "workers" in the second row includes subcategories listed in the UNEP/SETAC guidelines. The second "workers" in the third row includes social issues other than those listed in the guidelines covered by some studies; ${ }^{7}$ The stakeholder of "consumer" is not presented in this table, only [28] considers this stakeholder. 


\section{Data Level and Collection}

For practitioners, the data types and methods of collection remain critical issues when performing LCA analysis. Here, we point out the difference between the Environmental LCA (ELCA) and the SLCA data collection, as well as the "company-based" data used in SLCA and its potential inconsistency with the functional unit (FU) approach.

In LCA, FU must be established to enable different product systems to be compared on an equal basis [37]. This is not causing any controversies in ELCA, since the environmental impacts are directly linked with physical input/output of unit processes that are fulfilling the FU. However, such an approach is not feasible in SLCA because one measures the socioeconomic impacts, which are rather related to the behavior of a company instead of the function delivered by a given product [34,38]. This "company-based" concept is widely accepted by other methodology research (Figure 2). In order to use generic data (e.g., from statistical sources), the higher-level sector/industry/country data have been frequently used (Figure 2). The link to the FU can only be reserved when the "unit-process level" data are used (e.g., Hunkeler [9]) with the same unit-processes adopted from ELCA.

For data level categorization, most groupings in Figure 2 are the same as in Macombe et al. [39] who categorized the SLCA systems into three levels from the overall goal perspective: the system described as a chain of unit process, a chain of organizations/companies, and several countries in comparison. The first and second levels identified in Macombe et al. [39] correspond to unit-process and company levels in our grouping from the data perspective. The third level (i.e., inter-country comparison) in Macombe et al. [39] was not identified similarly in our grouping, instead, we specify two different data levels: sector/industry and country level and they are not constrained to be applied in inter-country comparison only. For this reason, Macombe et al. [39] classified the LCAA study [18] as a chain of organizations, we sorted it into both company level and higher sector/industry/country level data.

The "company-based" concept, meanwhile, leads to quite different data collection methods in SLCA from an ELCA. In ELCA, the data can either be collected through generic data (e.g., from environmental Life Cycle Inventory databases) or site-specific unit-process data. In SLCA, the data can also be collected from a generic/desktop search or site-specific data, but the generic data often uses statistical data, an input/output database, and publicly available company reports, which are not as easily collectable as using an inventory database in ELCA. Site-specific data is often collected through surveys and interviews (Figure 2). It is common practice for different data collection methods to be applied in the same study. For example, in the LCAA method proposed by Andrews et al. [18], all of the different data collection methods are necessary.

When data is collected at the company level, it raises the contradiction between requiring a FU approach and taking the "company-based" concept [40]. Parent et al. also asked "Is the quantitative relation between the indicator result and the functional unit of the product the only way to allow the representation of the product function's social aspects?" [6] and "Should the results be aggregated and reported on FU basis" [41]? We left the answers to the readers. For some studies, the results are kept at the company level and not allocated to the final FU (e.g., Dreyer et al. [19]). 


\section{Indicators}

Indicators act as the bridge that links the data with subcategories and impact categories, guiding the data collection process. Often, indicators are developed as a direct measurement of some social issues although the indirect indicator was first proposed in Dreyer et al. [19,20]. In SLCA, both qualitative and (semi)quantitative indicators are used.

The data collected are often types of direct indicators (Figure 2), which directly measure the impact themselves. Some authors [19-22] suggested the use of indirect indicators because the direct indicators often fail to explain the complexities associated with social issues (In [20], the problem of using direct indicators are identified. For example: Is there systematic registration of relevant data (In [20], the problem of using direct indicators is identified. For example, is there a systematic registration of the relevant data, like the registration of on-site accidents)? Would the disclosed data truly reflect the situation? Take child labor, for example - the company may introduce a child to a working life by allowing him or her to take on work that is appropriate for their age and maturity level in order to provide them the opportunity to gain skills or enhance their family's well-being). In Dreyer et al. [20], the indirect indicators assess companies' efforts of integrating managerial measures that are appropriate to the social issues, at three levels/dimensions of managerial measures [19,20] (Table 2). Aparcana and Salhofer [21] applied three indirect indicators out of 26 total indicators, but they only measured the formal policies paralleling to the first dimension of Dreyer et al. [19,20] where the implementation and effectiveness of the policies are not assessed. Hsu et al. also incorporated hybrid approaches where both direct and indirect indicators were used [23]. Similar to Dreyer et al. [19,20], each indicator in Hsu's method has three levels of fulfillment.

Indicators can be of qualitative or (semi)quantitative nature (Figure 2). For indicators that use data collected through interviews/surveys, they are often of a qualitative nature (i.e., textual description). In order to aggregate/link them to (sub)impact categories, qualitative data should be further processed into quantitative scores (e.g., scaling to a score of 1/0 for survey with "yes"/“no" in type I models, or $1 / 0$ to represent "certified"/"not certified" in LCAA). We define these types of indicators as (semi)quantitative. Quantitative indicators are those represented by numeric data (e.g., number of accidents). Qualitative indicators are those with textual description only, for example, Gauthier [33], and Franze and Ciroth [24] applied qualitative description.

\section{Impact Assessment}

This section focuses on discussions about the characterization models (type I and type II models) developed within each method, shown as the smallest circle presented in Figure 1, and the LCAA method (Figure 1). Characterization is the first step (and sometimes the only step) in life cycle impact assessment that aggregates the inventory to impact categories. According to the UNEP/SETAC guidelines, there are two types of characterization models: type I and type II [7]. "Type I impact categories aggregate the results for the subcategories within a theme of interest to a stakeholder, Type II impact categories model the results for the subcategories that have a causal relationships defined on the criteria" [7]. The type I characterization model does not incorporate causal relationships and the indicators are aggregated with a scoring system (i.e., aggregation by simple summation ( $\sum$ in Figure 3$)$ ). Type II characterization model is more similar to what has been adopted by Environmental Life 
Cycle Impact Assessment (ELCIA) for many years, where the inventory is linked with midpoint and endpoint impact categories through impact pathways, causal-effect chains/causal relationships (Figure 3); $\mathrm{f}(x)$ in Figure 3 means that certain function (e.g., regression) is involved in calculating the causal relationships. Different from the methods incorporating type I/II characterization models, LCAA is a new LCA method (see Section 5.3). As a stand-alone method, LCAA should not be considered as parallel to type I/II models.

Figure 3. Characteristics of the type I/II characterization model.

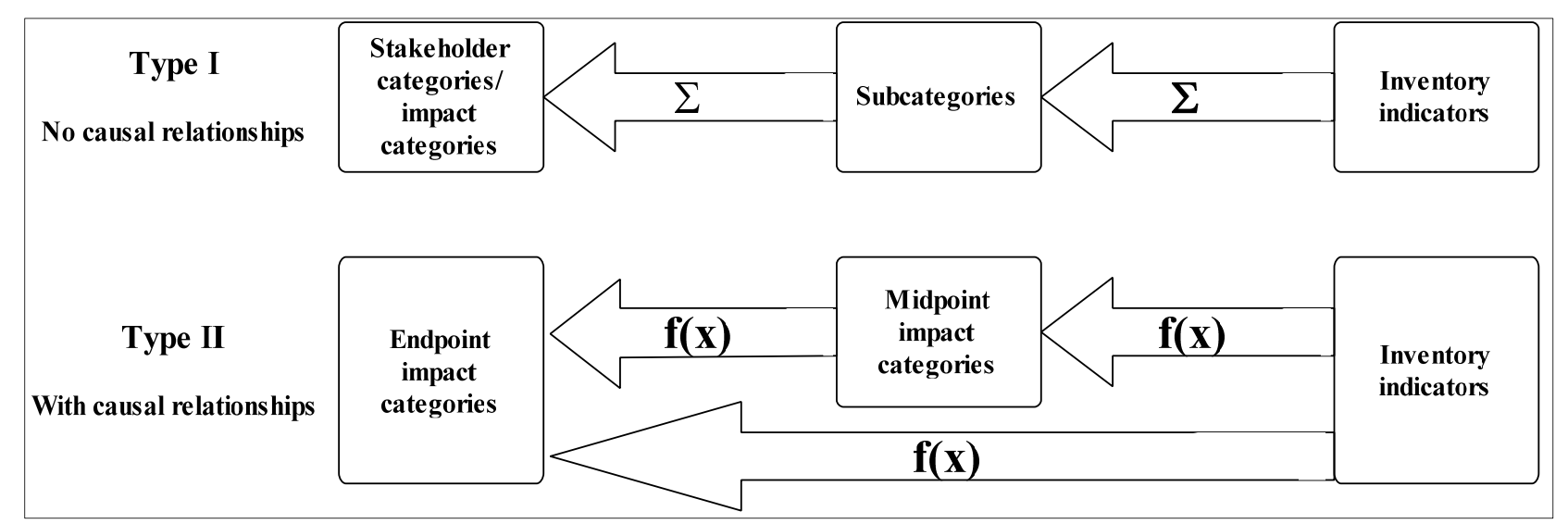

Notes: The type I model is based on a scoring system with simple aggregation from indicators to subcategories and impact categories; the type II model is based on the causal relationships from indicators to $\mathrm{mid} / \mathrm{end}$ point impact categories.

\subsection{Methods Incorporating Type I Characterization Models}

Different type I models seem to fall to groups that share similarities. We summarized each model according to: the scoring system such as multi-level scores for indicators or two levels ("yes" or "no" type) of scores, final aggregation (e.g., subcategory, impact category, or final single score), the weighting method, the geographical specification (if any), the product system specification (if any), and the scope of the case study/example (if any) (Table 2).

The methods developed by Schmidt et al. [8], and Hsu et al. [23], are the only ones that have a geographical specifications due to the application of country-specific weighting (Table 2); thus, they cannot be directly applied to studies outside the specified region. For the method of Schmidt et al. [8], although previous authors identified it as using type II models [42], we considered it using type I models because no impact pathways were established/linked with indicators to the Areas of Protection (AoP). The indicators are aggregated using different weighting factors: the relevance weighting factors indicate the extent to which the products or processes examined contribute to the social issues at the national (Germany) level; and the subjective weighting factors examine the general importance of each indicators by polling experts [8]. The overall weighting factor for each indicator is the geometric mean of the two weighting factors and a final single score is obtained by aggregation. Similar to the relevance weighting factors used in Schmidt et al. [8], Hsu et al. developed a method for assessing the social performances of the products and companies in Taiwan [23], with a focus on the stakeholder of workers following the UNEP/SETAC guidelines. Some managerial indicators are measured indirectly, like in [20,23]. 
Table 2. Characteristics of methods incorporating type I characterization models based on indicator scoring level, aggregation point, weighting method, geographical specification, product system specification, and case study scope.

\begin{tabular}{|c|c|c|c|c|c|c|}
\hline Method & Score Level & Aggregation Level & $\begin{array}{l}\text { Weighting } \\
\text { Based on }\end{array}$ & $\begin{array}{l}\text { Geographical } \\
\text { Specification }^{1} \\
\end{array}$ & $\begin{array}{l}\text { Product System } \\
\text { Specification }^{2} \\
\end{array}$ & Case Study/Example Scope ${ }^{3}$ \\
\hline Schmidt et al. 2005 & Multi-level & Final single score & $\begin{array}{l}\text { Relevance and panel } \\
\text { weighting }\end{array}$ & Germany & General & N.A. \\
\hline Hsu et al. 2013 & Multi-level & Subcategory & Relevance weighting & Taiwan & General & N.A. \\
\hline Aparcana and Salhofer 2013 & Two-level $(1$ or 0$)$ & Subcategory & No weighting & No specification & $\begin{array}{l}\text { Recycling system in } \\
\text { low-income countries }\end{array}$ & Grave to grave $* 4$ \\
\hline Foolmaun and Ramjeeawon 2013 & Two-level (yes or no) & Final single score & Equal weighting & No specification & EoL of PET bottles & Grave to grave $* 4$ \\
\hline Vinyes et al. 2013 & Multi-level & Final single score & Equal weighting & No specification & EoL of used cooking oil & Grave to grave $* 4$ \\
\hline Manik et al. 2013 & Multi-level & Final single score & Panel weighting & No specification & $\begin{array}{l}\text { Palm oil biodiesel system } \\
\text { in Indonesia }\end{array}$ & Cradle to gate * \\
\hline Dreyer et al. 2010 & $\begin{array}{l}\text { Multi-level (and } \\
\text { multi-criteria }{ }^{5} \text { ) }\end{array}$ & Subcategory & No weighting & No specification & General & $\begin{array}{l}\text { Company risk scores obtained for } 6 \\
\text { companies, without further allocation to } \\
\text { product/functional unit }\end{array}$ \\
\hline Hutchins and Sutherland 2008, part 2 & Multi-level & Final single score & Panel weighting & No specification & General & Gate to gate \\
\hline Franze and Ciroth 2011 & Multi-level & Subcategory & No weighting & No specification & General & Gate to gate \\
\hline Ciroth and Franze 2011 & Multi-level & Impact categories & Equal weighting & No specification & General & $\begin{array}{l}\text { Cradle to grave } * \\
\text { (except use and re-use stage) }\end{array}$ \\
\hline Hosseinijou et al. 2013 & Multi-level & Impact categories & Panel and equal weighting & No specification & Materials comparison & Cradle to grave * \\
\hline Martínez-Blanco et al. 2014 & Multi-level & Subcategories & No weighting & No specification & Fertilizer alternatives & Cradle to grave * \\
\hline Ekener-Petersen and Finnveden 2013 & Multi-level & Subcategories & No weighting & No specification & General & Cradle to grave \\
\hline
\end{tabular}

Notes: ${ }^{1}$ Geographical specification: "no specification" means that it can be directly adopted to future studies without further adjustment of the impact assessment method; "country name-specific" means that the normalizing/weighting is country-specific and needs to be adjusted for future studies (e.g., weighting method of Schmidt et al. 2005 and Hsu et al. 2013 apply the country-level statistic data for Germany/Taiwan); ${ }^{2}$ Some methods are developed to specifically study a particular product system; thus, the social issues covered and (sub)categories identified are related to a particular product system. Nevertheless, the characterization model is not affected by the selection of indicators/(sub)categories; ${ }^{3}$ Case study means that a real-world case was analyzed and is indicated by *; example means a hypothetical study; ${ }^{4}$ Grave-to-grave means that only the EoL stage was analyzed; ${ }^{5}$ Multi-criteria means that three levels of criteria are measured (a. establishing of guidelines and practices; b. the communication and delegation of responsibility for integration into daily work; c. systematic active control of the integration). The scores of the three levels are multiplied to obtain the score for each managerial measure. 
The methods developed by Aparcana and Salhofer [21,22], and Foolmaun and Ramjeeawon [25], use a two-level scoring system for indicators (Table 2). The former method is developed to assess the recycling systems in low-income countries [21,22] and the latter to compare different End of Life (EoL) scenarios for PET bottles in Mauritius [25]. In Aparcana and Salhofer [21,22], 1 or 0 is assigned to each indicator for the fulfillment or non-fulfillment of the social compliance criteria [21,22] so that an average score for each indicator is obtained as the proportion of stakeholders affirming fulfillment of the criterion, resulting in a final score of 1 (if the proportion is over 50\%) or 0 [21,22]. When aggregating at the subcategory level, the subcategory score is 1 only if all of the indicators under this subcategory are 1. In Foolmaun and Ramjeeawon [25], qualitative interview data with "yes" or "no" answers were converted to percentage data and followed up by a single score (i.e., 0 to 4, according to the percentage number). The scores were summed to a final single score with equal weighting for each subcategory. The simple two-level scoring systems are used probably due to one common trait of their product system: the targeted stakeholders involved tend to have low-education backgrounds (e.g., the recyclers); thus, the use of the "yes" or "no" type of question may facilitate the data collection. This may be adopted for similar future studies.

Vinyes et al. compared different collection schemes for used cooking oil in Barcelona from environmental, economic, and social perspectives [10]. For SLCA, data collected for indicators are transformed to contribution percentages, where the product system with the highest indicator value has a contribution of $100 \%$ [10]. Similar to Foolmaun and Ramjeeawon [25], the percentage data are converted to scores from 1 to 5 [10]. Scores for different indicators are summed over as a single social indicator, without aggregation into subcategories or impact categories.

Manik et al. developed a method to assess the palm oil biodiesel system in Indonesia using a seven-point Likert scale [26]. Stakeholders were asked for their social expectation and the social perception of each social criterion of the product system [26]. This multi-level scoring system differs from the "yes or no" types of indicators, reflecting different scales on how the actual performance to a reference situation is satisfied. Experts were participated in panel weighting [26]. The gap between the expectation and the perception was then multiplied with the weight of each criterion before aggregating to a single score [26].

The methods in Dreyer et al. [20] and second part of Hutchins and Sutherland [27] converted the company-based score to the product-based (i.e., FU) score using a "product relation factor" that expresses the weight of the social risk profile of a company in a life cycle shall be given [17,20]. Dreyer et al. proposed a type II model-based framework in 2006 [17] and later developed a method based on the type I model for the characterization of a single social issue: labor rights [20]. The indirect indicator scores were constructed using a scoring matrix and adjusted according to the context risk (by context, the authors mean the external environment characterizing the risks of negative impacts.), through multiplying a contextual adjustment factor (i.e., the probability of occurrence in context) [20]. Hutchins and Sutherland developed a type I characterization model with four categories [27]. Each category was presented by one quantitative indicator in the form of a ratio of performance (for example, for the category of labor equity, the indicator value is obtained as the ratio of the average hourly labor cost to the total compensation package for the company's highest paid employee; for safety, it is obtained as the ratio of average days with no injuries to the total days worked per employee). The final aggregated score for a single company was generated through panel weighting. 
In the methods developed by Ciroth and Franze [15], and Hosseinijou et al. [12], the authors separated the results by life cycle stage, known as the "cradle-to-grave" studies (Table 2). Such separation is not observed in other studies using type I models. Ciroth and Franze's method is based on a color scale [15]. A score ranging 1 to 6 is assigned to each color for the quantification of the impacts. In an earlier version of a similar method [24], it has a five color scale and that is not transferred to a score. The method proposed by Hosseinijou et al. differs from the others in two ways. Firstly, a hot spot assessment is carried out using a material flow analysis and stakeholders' and experts' interviews, resulting in the most pressing social issues along the life cycle for identified stakeholders [12]. Secondly, based on the hot spot identified, a site specific analysis is carried out, using a pairwise comparison method of the analytic hierarchy process [12].

The method proposed by Martínez-Blanco et al. [28] assessed the sustainability of fertilizer alternatives. Similar to Ciroth and Franze [15], and Hosseinijou et al. [12], it also carried out a "cradle-to-grave" case study and reported results at the final FU. In order to link social aspects along the supply chain to the FU, the indicators are weighted by the relative importance of processes on the life cycle and then aggregated. The relative importance is represented by the coefficients of working time of the processes (i.e., seconds of work per FU), following the approach of LCAA (see Section 5.3).

Using a general (imaginary) laptop example, Ekener-Petersen and Finnveden established a unique approach for the hotspot identification of a product category [14]. The method stringently adopts the stakeholder categories and subcategories from the UNPE/SETAC guidelines. For the impact assessment, using a matrix form, the hotspots are identified by combining: (1) vertical columns representing the country activity in certain life cycle stage; and (2) horizontal rows representing each country's performance on the indicators. The hotspots are those where vertical and horizontal highlights coincide. For the vertical columns, the determination of the activity level for each country is done through global statistics. The data collected in this way only identifies which countries are highly involved for different processes. It conveys no information of the production chain of a laptop since these raw materials are used in hundreds of different sectors. Similarly, for the horizontal rows, the indicator value and thus the social performance of each country is not particularly linked to the production of the laptop. For these reasons, we consider this method to be a generic social-hot spot identification method at the country level, similar to the SHDB (SHDB is a global database that aims to identify a hotspot within a certain sector of certain country. It incorporates type I model when identifying social risks and opportunities).

The indicators chosen in the Ekener-Petersen and Finnveden method need to be discussed here. For example, to assess the subcategory of "delocalization and migration" for the stakeholder of local communities, one of the indicators measured is "International migrants as percentage of population" [14]. Do more international migrants mean the better performance on "delocalization and migration"? Similar issues are encountered by other type I models when linking subcategories to final impact categories, based on authors" "own thoughts" [15]. This "relativity" issue of the type I model is further discussed in Section 6.

\subsection{Frameworks/Methods Incorporating Type II Characterization Models}

In contrast to the booming of the methods with type I models since the publication of the UNEP/SETAC guidelines, many of the frameworks/methods incorporating type II models were proposed earlier $[9,17,29,30]$. Some type II models were proposed within a general framework $[13,17,29,43]$, 
thus, not providing many details or case studies as compared to the methods with type I models. Another difference from the type I models is that normalization steps are involved in some of the type II models [29,30], due to which, causing the geographical specification constrained accordingly (Table 3).

For the type II models, we categorized them into two groups: (1) with a single impact pathway that measures a single social issue; and (2) with multiple impact pathways that measure multiple social issues. We summarized the frameworks/methods with type II models according to: single/multiple impact pathway(s), the causal relationships along the impact pathway(s), the normalization/weighting methods involved in the process, geographical specification, and case study scope (Table 3).

Single Impact Pathway: The methods developed by Norris, Hutchins and Sutherland, and Feschet et al. identified the single pathway by focusing on the AoP of human health [27,31,32]. They attempted to establish causal relationships between economic development (GDP or GNP per capita) and national health improvement.

Hutchins and Sutherland used the UN's Human Development Report of 2005 to establish a non-linear regression model to describe the impact pathway from the GDP per capita in the purchasing power parity (PPP) to the infant mortality rate [27]. This method assumes a company has the choice over the selection of suppliers from rich or poor countries. When choosing poor countries, the economic change would result in a more obvious reduction in infant deaths. When choosing rich countries, the economic change would be insignificant for infant mortality. Similarly, in the case study of Norris [31], the health benefit to non-OECD countries showed significant compared to the health damages from pollution due to their involvement in the Dutch electricity distribution.

Both Norris [31], and Feschet et al. [32], re-constructed the Preston curve (i.e., the empirical relationship between the links of life expectancy and the income per capita) using different regression models. Norris regressed the mean life expectancy on the GNP per capita at birth year based on 1999 PPP by identifying and adding two positive impact pathways between GDP and health outcome: (1) the increased incomes of the poor; and (2) the increased public expenditure through increased taxes [31]. The author pointed out that the model was a coarse screening method. It is recognizable that the true causality (and thus the impact pathway) could not be easily demonstrated from a statistical point of view due to issues, such as data availability, down/up-scale of data, choice of statistic models, etc. Thus, previous studies are conditioned by certain technical constraints, which may include a series of questions such as: (1) Do the increased incomes benefit the people in most need (e.g., the health statuses of the poor tend to have a stronger co-relations with the increased income)? (2) Do the increased taxes actually reach the increased public expenditure on health? (3) Is the scale-up from a micro-economy (e.g., company level output) to the macro-economy (e.g., country GDP) valid? (4) The regression model based on 2002 data from the World Bank, is it still valid to predict future situations while the GDPs and populations are all dynamically changing through time? (5) Is this kind of country level analysis representative of sectional or provincial differentiation? (6) The non-linearity between economic growth and health output (e.g., small changes in the most poor countries correlate well with larger increases in health outputs), what is the role of this correction in affecting the model results? In addition, (7) The time lag between economic development and improved social service, would the authors yield a similar conclusion when time is considered? 
Table 3. Characteristics of frameworks/methods incorporating type II characterization models based on impact pathway(s), normalizing/weighting method, geographical specification, and case study scope.

\begin{tabular}{|c|c|c|c|c|c|c|}
\hline Framework/method & $\begin{array}{l}\text { Impact } \\
\text { Pathway(s) }\end{array}$ & Causal Relationships & $\begin{array}{l}\text { Midpoint } \\
\text { vs. Endpoint }\end{array}$ & $\begin{array}{l}\text { Normalizing, } \\
\text { Weighting }\end{array}$ & $\begin{array}{l}\text { Geographical } \\
\text { Specification }^{\#}\end{array}$ & $\begin{array}{l}\text { Case study/ } \\
\text { Example Scope }\end{array}$ \\
\hline Feschet et al. 2013 & Single & GDP per capita to life expectancy & Endpoint only & No & Global & Cradle to gate \\
\hline Norris 2006, part 1 & Single & GDP per capita to life expectancy & Endpoint only & No & Global & Cradle to gate * \\
\hline $\begin{array}{l}\text { Hutchins and } \\
\text { Sutherland 2008, part } 1\end{array}$ & Single & GDP per capita to infant mortality & Endpoint only & No & Global & Gate to gate \\
\hline Dreyer et al. 2006 & Multiple & Not specified & $\begin{array}{l}\text { Midpoint and } \\
\text { endpoint }\end{array}$ & Not specified & Global & N.A. \\
\hline Weidema 2006 & Multiple & $\begin{array}{l}\text { Dozens of impact pathways, } \\
\text { refer to original document }\end{array}$ & $\begin{array}{l}\text { Midpoint and } \\
\text { endpoint }\end{array}$ & $\begin{array}{l}\text { Global normalization; } \\
\text { Monetization weighting }\end{array}$ & Global & N.A. \\
\hline Hunkeler 2006 & Multiple & $\begin{array}{l}\text { Carrying out of unit process to labor hours } \\
\text { to affording social needs }\end{array}$ & Midpoint only & $\begin{array}{l}\text { Egalitarian (equal) weighting } \\
\text { for each impact category }\end{array}$ & No specification & Cradle to gate * \\
\hline $\begin{array}{l}\text { Brent and } \\
\text { Labuschagne } 2006\end{array}$ & Multiple & $\begin{array}{l}\text { Dozens of impact pathways are constructed, } \\
\text { refer to original document. }\end{array}$ & $\begin{array}{l}\text { Midpoint and } \\
\text { endpoint }\end{array}$ & $\begin{array}{l}\text { South Africa normalization; } \\
\text { distance-to-target weighting }\end{array}$ & South Africa & Three projects * \\
\hline Jørgensen et al. 2010 & Multiple & $\begin{array}{l}\text { Non-production to decrease in labor demand } \\
\text { to unemployment to health; poverty; family } \\
\text { tension; violence and crime }\end{array}$ & Not specified & Not specified & No specification & N.A. \\
\hline
\end{tabular}

Note: "It serves the same mean as that in Table 2. Both "no specification" and "global" mean that it can directly adopted to future studies without further adjustment of the impact assessment method. All type II model-based frameworks/methods are developed to serve general purposes (not focused on a specific product category/industry); thus, the product system specification (Table 2) is not identified here; * Similar to Table 2, the real-world case studies are indicated by *; otherwise, they are hypothetical examples. 
While Norris's model can be used for inter-country comparison, Feschet et al. further elaborated the characterization model to incorporate time scales for understanding the dynamic behavior (i.e., the varying situations of individual countries over time) and variation among countries [32]. This alleviates the fourth and seventh problems mentioned above. In addition, Feschet et al. emphasized that four conditions should be met when applying their model [32]: (a) the activity happens within countries where the GDP per capita in PPP is $<\$ 10,000$ at the start point, which alleviates the sixth problem above; (b) the activity should account for a significant part of the total GDP, which addresses the third problem; (c) the duration of the activity is regular and long enough, based on the authors' time series analysis (showing a four-year lag between the economic growth and health improvement), which addresses the seventh problem; and (d) the added value is shared within the country, which may guarantee the positive answer to the first problem. Other problems are still too hard to address due to the inherent technical constraints. Furthermore, while for the least developed countries, it is both intuitively true and statistically validated, as in Feschet et al. [32], that the economic growth leads to health improvement. For other countries, the causal relationships may also be reversed (i.e., does better national health causes more productivity and economic growth?).

Multiple Impact Pathways: Frameworks/methods incorporating type II characterization models with multiple impact pathways try to model the causal relationships between indicators to more than one midpoint and/or endpoint impact categories (Table 3). Most models belong to frameworks instead of methods.

Three early frameworks/methods using type II models are from Dreyer et al. [17,44], Weidema [29] and Brent and Labuschagne [30]. Both Dreyer et al., and Weidema, proposed the final AoP as "human dignity and well-being" [17,44]. In Dreyer et al., two classes of impact categories were identified as obligatory and optional $[17,44]$. Weidema identified six damage categories and aggregated them to a comprehensive indicator - Quality Adjusted Life Years [29], which is analog to the well-documented Disability Adjusted Life Years from ELCIA. A top-down approach (i.e., starting from the damage categories) is used when constructing impact pathways [45]. The estimate of global normalization values is proposed for the first time, with the global level of well-being of $29 \%$ of the full well-being at the time of the analysis [29]. Brent and Labuschagne also used a top-down approach, with AoP identified and then end-point categories linked to the AoP. Each end-point category is linked from a total of 19 mid-point categories) [30]. Some of the inventory indicators link directly to the end-point categories without linking to the mid-point categories [30] (Figure 3). Although Brent and Labuschagne [30] focused on the application of the method for project and technology assessment from a management perspective [30], suggesting that the life cycle phases maybe are different from the product-based assessments (the construction phase, the operation phase, and the decommissioning phase), the structure of the characterization model is applicable for product assessment.

Another earlier type II model was proposed by Hunkeler in a geographically specific mid-point based societal LCA for comparative product assertions [9]. The key feature of the method is to introduce an intermediate variable-labor hours. The causal relationships are not established like in other type II models. Instead, the labor hours' requirements for each unit process in a specific geographical location were used and translated into a unit of societal needs (e.g., housing). The comparative results between alternative products are kept at the mid-point level after an equal weighting for each impact categories. In the case study, four impact categories were developed: housing, health care, education, and 
necessities [9]. This method has great potential to be applied by customizing the impact categories and following the same calculation procedures for other practitioners.

More recently-developed frameworks include Jørgensen et al. [13], Lagarde and Macombe [11] and Reitinger [16]. Both Jørgensen et al., and Lagarde and Macombe, proposed "consequential SLCA" frameworks, while Jørgensen et al. incorporated type II models and Lagarde and Macombe did not specify any particular characterization models. In Jørgensen et al., the social consequences of non-implemented product life cycles are identified, with the differences between consequential SLCA and consequential ELCA considered [13]. The impact pathway from non-production to unemployment is recognized based on the empirical evidences of Carlsson's study [13,46]. Based on Hakim [47], the impact pathway from unemployment to four impact categories is further included: the physical health and mental health of the unemployed, poverty, family tension, and violence and crime [13]. Depending on the socio-economic status of the un-employed individuals, the degrees of impacts vary among individuals and, thus, "modifying factors" is adopted to measure how "effective" unemployment may influence the impacts [13]. In addition to adjusting for the un-employed at the individual level, it seems that the background context (e.g., social security) should also be a part of the "modifying factors".

The goal of Lagarde and Macombe's paper is to propose a framework for identifying the organizations involved in the social life cycle of a product within the context of competition [11]. It does not specify characterization models thus are not included in Table 3. In the case study, only the number of potential jobs removed/created was measured at the indicator level [11]. It identifies the relevant organizations using consequential thinking derived from consequential ELCA: "the organizations to include in the social life cycle of product $\mathrm{X}$ are those that would change their behavior that has a significant social effect in response to a change in the scenario to produce $X$ " [11]. Accordingly, the cut-off criteria are defined as significant dependency criteria. The same questions are raised as in ELCA for the cut-off criteria: How significant is significant? Should the "significance" be $5 \%$ of total impacts, as used in many ELCA studies as a general rule of thumb?

For the framework of Reitinger et al., it is hard to identify its characterization model because the framework was developed at a general level from the philosophical perspective and with a capability approach [16]. The framework proposes AoP and employs the seven dimensions of human lives (life itself; knowledge and aesthetic experience; some degree of excellence in work and play; friendship; self-integration; self-expression; transcendence) as impact categories [48-50]. Except for the seven dimensions for individual aspects, an eighth impact category_- "fairness" is also included [16,43]. We consider that the framework can be further improved toward a method incorporating either a type I or a type II model. For example, to be developed into a type I model, capabilities, as subcategories, can be simply aggregated to the eight impact categories. To be developed into a type II model, one needs to identify the quantitative causal relationships between the subcategories (i.e., the capabilities) and the impact categories (i.e., the dimensions of lives), as well as AoP. Because we could not identify its model type, it was not included in Tables 2 and 3.

\subsection{Life Cycle Attribute Assessment}

LCAA measures the share of relevant activity across a life cycle that has attributes of interest [31]. It asks question such as "what percentage of my supply chain has attribute X?" [18]. More specifically, in a format like " $40 \%$ of my supply chain is SA 8000 certified". This method was originally proposed by 
Norris [31] in the hope of using site-specific information provided by the proliferating set of certification systems [31], such as those of OHSAS 18001, SA8000, Forest Stewardship Council (FSC) certification. Consequently, Andrews et al. [18] elaborated the method by detailing the steps and calculation procedures for LCAA. The mechanisms of the LCAA works in a similar way to the traditional LCA computation [51], interested readers can refer to Figure A1 for a further discussion on the computational structure of LCA and LCAA.

The LCAA proposed by Andrews et al. mirrors that of Hunkeler's method. The difference is that only statistical data sources of labor hours are used in Hunkeler's method, whereas in Andrews et al., both the general statistical data of labor hours and site-specific data are collected for the foreground system. In the future, the Worker Hours Model developed by the SHDB [35] may be used for the labor hours of the background system for the LCAA, which may potentially ease the burden in data collection. Nevertheless, the data requirement is always high for LCAA because it requires both background and foreground relevant activity flows that are not readily available (unlike in ELCA, the environmental flows are available and do not need to be collected by the practitioners).

There are no normalizing/weighting steps involved in LCAA. The characterization model here only assigns an explicit value of " 0 ", "1" or "unknown" (i.e., non-certified, certified, unknown) and thus avoids the uncertainty caused by the invalidity of the impact pathway as in type II characterization models [42]. It should be noted that LCAA is a new way of modeling LCA and, thus, not exclusively applicable to the social dimension.

Similar to the potential problems in "whether the data provided by a company can truly reflect the situation" when measuring direct indicators [20], the validity of certification system needs to be taken into account in LCAA. In some parts of the world where cultural background allows for high tolerance of fraudulence and furious competition between third-party certification organizations, the company can easily obtain the certificate without showing true compliance. The comparison between LCAA and methods incorporating type I/II models is provided in Section 6.

\section{Discussion and Conclusions}

We reviewed recent advancements in SLCA frameworks, methods and characterization models. While a brief discussion of the goals, data, and indicator levels were provided in Sections 2 through 4 for different frameworks/methods, the focus of this review is placed on the discussion of characterization models for the impact assessment of different frameworks/methods.

At the impact assessment level, both type I and type II models have advantages and disadvantages. Type I models may avoid the uncertainties of impact pathways, but face the problem of ensuring whether the indicators are relevant for the stakeholders [42]. These problems can be avoided by carefully choosing companies to be included in the perimeters and selecting the relevant indicators [11]. Although type I models do not incorporate impact pathways inherently, the formations of impact pathways in some cases need to be convincing for practitioners/developers that selected indicators are relevant and representative for the corresponding subcategories. Clear linkage between subcategories and impact categories needs to be established. A mixed use of type I and type II models seems plausible in this regard. Type II models, on the other hand, follow a standard LCIA approach. During the impact assessment, the different choices of impact categories are not as methodically important as for the different choices of the characterization models [6]. Likewise, the choice of AoP is not important 
because it does not contain much information. The importance lies in the identification of the impact pathways that most closely and accurately represents the real situation. More uncertain than the ELCIA model, in SLCIA, different social/cultural context, time-scales, and scales of the change indicate that a universal impact pathway may not be obtainable, making the situation more complicated. More valid impact pathways may be established, as Jørgensen et al. suggested, by introducing new indicators, but this is practically hard to achieve [42].

For methods incorporating type I models, we emphasize the importance of specifications for the product system (Table 2). Some methods are developed for assessing specific product chains. Although such product specification may apparently reduce the adoptability of the method for future studies, it assures both the SLCA itself, and later on, the managerial effort and focus on the materiality issues (by definition, materiality is the threshold at which aspects become sufficiently important that they should be reported. The new focus on materiality in G4 means that sustainability reports will be centered on matters that are very critical for achieving an organization's goals and for managing its impact on society [52]). From the materiality issues perspective, how broad the method covers social issues (Table 1, Figure 2) is not important and should not be used to judge the effectiveness of a method. As pointed out by Lagarde and Macombe [11], the UNEP/SETAC guidelines may not be systematic in a sense of identifying the relevant stakeholders and materiality issues by stating "consultants and researchers risk unintentionally overlooking some seriously affected actors, and therefore miss the principal social impacts of a product" [11]. To address the problems, Lagarde and Macombe proposed methods for identifying relevant stakeholders conditioned on the product system and its boundaries [11]. The systematic identification of "materiality issues" in SLCA remains a priority. A promising approach is to learn lessons from tools such as the GRI.

One of the common traits of the methods and the case studies conducted are the partial life cycles (Tables 2 and 3). Correspondingly, most methods put emphasis on the coverage of social issues on workers, while the stakeholders of consumer and value chain actors are rarely considered (Table 1). Although some authors covered social issues with additional indicators, they focused either on the stakeholder of workers or product, project, and technology-specific indicators [53]. The partial LCA may reflect the statement that "companies need to assess only those parts that they have an influence on" [17,38]. Such partial LCA is categorized as management SLCA by Jørgensen et al. [54,55]. LCAA assesses the product supply chain and is based on input/output tables. Therefore, it may not be able to include use and EoL stages. Methods incorporating type I and/or type II models can include use and EoL stages, but the data collection would be more challenging than accessing company data.

Different from type I/II models, LCAA either encounters the relativity issues that may present in type I models, or face the uncertainty problems during modeling impact pathways. Nevertheless, LCAA is not considered as a superior method over methods with type I/II models because the difference is due to the fact that LCAA asks questions that are different from those LCA approaches.

Another interesting phenomenon is the development of different frameworks/methods/models by the same author(s) [17,20,27], reflecting the inherent diversity feature of SLCA. As stated by Zamagni [56] "SLCA has been sketched at a methodological level". Clearly, it is of overriding importance to apply the developed frameworks/methods, and/or to test the existing impact assessment models, while awaiting new frameworks/methods emerge. 
One driver of the SLCA development is due to the increasing interest in Life Cycle Sustainability Assessment (micro/product level) and Life Cycle Sustainability Analysis (both micro/product and macro/societal level). For the micro level Life Cycle Sustainability Assessment, it is closely related to SLCA under the broad formula of Life Cycle Sustainability Assessment $=$ LCA + LCC (Life Cycle Cost) + SLCA [57-59]. For the micro and macro level Life Cycle Sustainability Analysis, one recent example is the EU-funded project-PROSUITE, which aims to develop a standardized methodology and free software for the evaluation of the sustainability of technologies that cover all three dimensions of sustainability [4,60]. Here, we focused on the reviews of stand-alone SLCA studies, however, some of the reviewed studies carried out both ELCA and SLCA separately [10,24,25]. When carrying out ELCA and SLCA at the same time, the same FU and system boundary cannot always be warranted. In a study comparing two different EoL scenarios for used computers, Laquerre and Brodeur demonstrated the potential inconsistency between ELCA and SLCA [61]. In another study [24], the transport is included for ELCA but not for SLCA. When the product system becomes more complex, the system boundary inconsistencies between ELCA and SLCA will increase substantially [15]. Martínez-Blanco et al. [15] also stated that the comparability and reliability of the SLCA results being challenged by the definition of the functional unit and the system boundaries among others. Other inconsistencies between ELCA and SLCA include the usage and acceptance of generic data, time sensitivity of data (e.g., social conditions change faster and require more updated data than ELCA). A harmonization is necessary and expected in the near future.

\section{Acknowledgments}

This material is based upon work supported by the National Science Foundation under CHE-1230246 to Yanfa Yan and others at the University of Toledo. The authors appreciate the valuable comments provided by the two anonymous reviewers.

\section{Author Contributions}

Dan Yang contributed to Section 5 and Section 6. Ruqun $\mathrm{Wu}$ contributed to all sections. Jiquan Chen contributed to the overall quality of the paper.

\section{Table of Abbreviations}

$\begin{array}{ll}\text { LCA } & \text { Life cycle assessment } \\ \text { SLCA } & \text { Social life cycle assessment } \\ \text { UNEP } & \text { United Nations Environment Programme } \\ \text { SETAC } & \text { Society of Environmental Toxicology and Chemistry } \\ \text { LCAA } & \text { Life cycle attribute assessment } \\ \text { SLCIA } & \text { Social life cycle impact assessment } \\ \text { SHDB } & \text { Social hotspot database } \\ \text { GRI } & \text { Global reporting initiative } \\ \text { ELCA } & \text { Environmental life cycle assessment } \\ \text { FU } & \text { Functional unit } \\ \text { ELCIA } & \text { Environmental life cycle impact assessment }\end{array}$



AoP
Areas of protection
PPP
Purchasing power parity
EoL
End of life
OHSAS Occupational health and safety management systems
FSC Forest Stewardship Council

\section{Appendix}

Table A1. SLCA frameworks/methods reviewed in this paper.

\begin{tabular}{|c|c|}
\hline Framework/method & Title of the publication \\
\hline Schmidt et al. 2005 & $\begin{array}{l}\text { SEEbalance }{ }^{\circledR} \text { : Managing sustainability of products and processes with the } \\
\text { socio-eco-efficiency analysis by BASF }\end{array}$ \\
\hline $\begin{array}{l}\text { Brent and Labuschagne } \\
2006\end{array}$ & $\begin{array}{l}\text { Social indicators for sustainable project and technology life cycle management in the } \\
\text { process industry }\end{array}$ \\
\hline Dreyer et al. 2006 & A framework for social life cycle impact assessment \\
\hline Hunkeler 2006 & Societal LCA methodology and case study \\
\hline $\begin{array}{l}\text { Norris 2006, part } 1 \\
\text { Norris } 2006 \text {, part } 2\end{array}$ & Social impacts in product life cycles-towards life cycle attribute assessment ${ }^{1}$ \\
\hline Weidema 2006 & The integration of economic and social aspects in life cycle impact assessment \\
\hline $\begin{array}{l}\text { Hutchins and Sutherland } \\
2008 \text {, part } 1 \\
\text { Hutchins and Sutherland } \\
2008 \text {, part } 2\end{array}$ & $\begin{array}{l}\text { An exploration of measures of social sustainability and their application to supply } \\
\text { chain decisions }{ }^{2}\end{array}$ \\
\hline Andrews et al. 2009 & Life cycle attribute assessment \\
\hline Jørgensen et al. 2010 & Defining the baseline in social life cycle assessment \\
\hline Dreyer et al. 2010 & $\begin{array}{l}\text { Characterisation of social impacts in LCA; } \\
\text { Characterisation of social impacts in LCA. part 2: implementation in six company case } \\
\text { studies }\end{array}$ \\
\hline Franze and Ciroth 2011a & A comparison of cut roses from Ecuador and the Netherlands; \\
\hline Ciroth and Franze 2011b & $\begin{array}{l}\text { LCA of an ecolabeled notebook-consideration of social and environmental impacts } \\
\text { along the entire life cycle }\end{array}$ \\
\hline Reitinger et al. 2011 & A conceptual framework for impact assessment within SLCA \\
\hline Aparcana and Salhofer 2013 & $\begin{array}{l}\text { Development of a social impact assessment methodology for recycling systems in } \\
\text { low-income countries; } \\
\text { Application of a methodology for the social life cycle assessment of recycling } \\
\text { systems in low income countries: three Peruvian case studies }\end{array}$ \\
\hline $\begin{array}{l}\text { Ekener-Petersen and } \\
\text { Finnveden } 2013\end{array}$ & Potential hotspots identified by social LCA-part 1: A case study of a laptop computer \\
\hline Feschet et al. 2013 & Social impact assessment in LCA using the Preston pathway \\
\hline $\begin{array}{l}\text { Foolmaun and Ramjeeawon } \\
2013\end{array}$ & $\begin{array}{l}\text { Comparative life cycle assessment and social life cycle assessment } \\
\text { of used polyethylene terephthalate (PET) bottles in mauritius }\end{array}$ \\
\hline
\end{tabular}


Table A1. Cont.

\begin{tabular}{ll}
\hline Framework/method & Title of the publication \\
\hline Hosseinijou et al. 2013 & $\begin{array}{l}\text { Social life cycle assessment for material selection: a case study } \\
\text { of building materials }\end{array}$ \\
\hline Hsu et al. 2013 & Development of a New Methodology for Impact Assessment of SLCA \\
\hline Lagarde and Macombe 2013 & Designing the social life cycle of products from the systematic competitive model \\
\hline Manik et al. 2013 & $\begin{array}{l}\text { Social life cycle assessment of palm oil biodiesel: a case study in } \\
\text { Jambi Province of Indonesia }\end{array}$ \\
\hline Vinyes et al. 2013 & Application of LCSA to used cooking oil waste management \\
\hline Martínez-Blanco et al. 2014 & $\begin{array}{l}\text { Application challenges for the social LCA of fertilizers within } \\
\text { Life Cycle Sustainability Assessment }\end{array}$ \\
\hline
\end{tabular}

Notes: ${ }^{1}$ Norris's paper has two parts: the first part of the paper incorporates type II characterization model and the second part introduces LCAA; ${ }^{2}$ Hutchins and Sutherland's paper has two parts: the first part of the paper incorporates the type II characterization model and the second part of the paper incorporates the type I characterization model.

Figure A1. Similarities and differences of the computational structures between the LCA and LCAA.

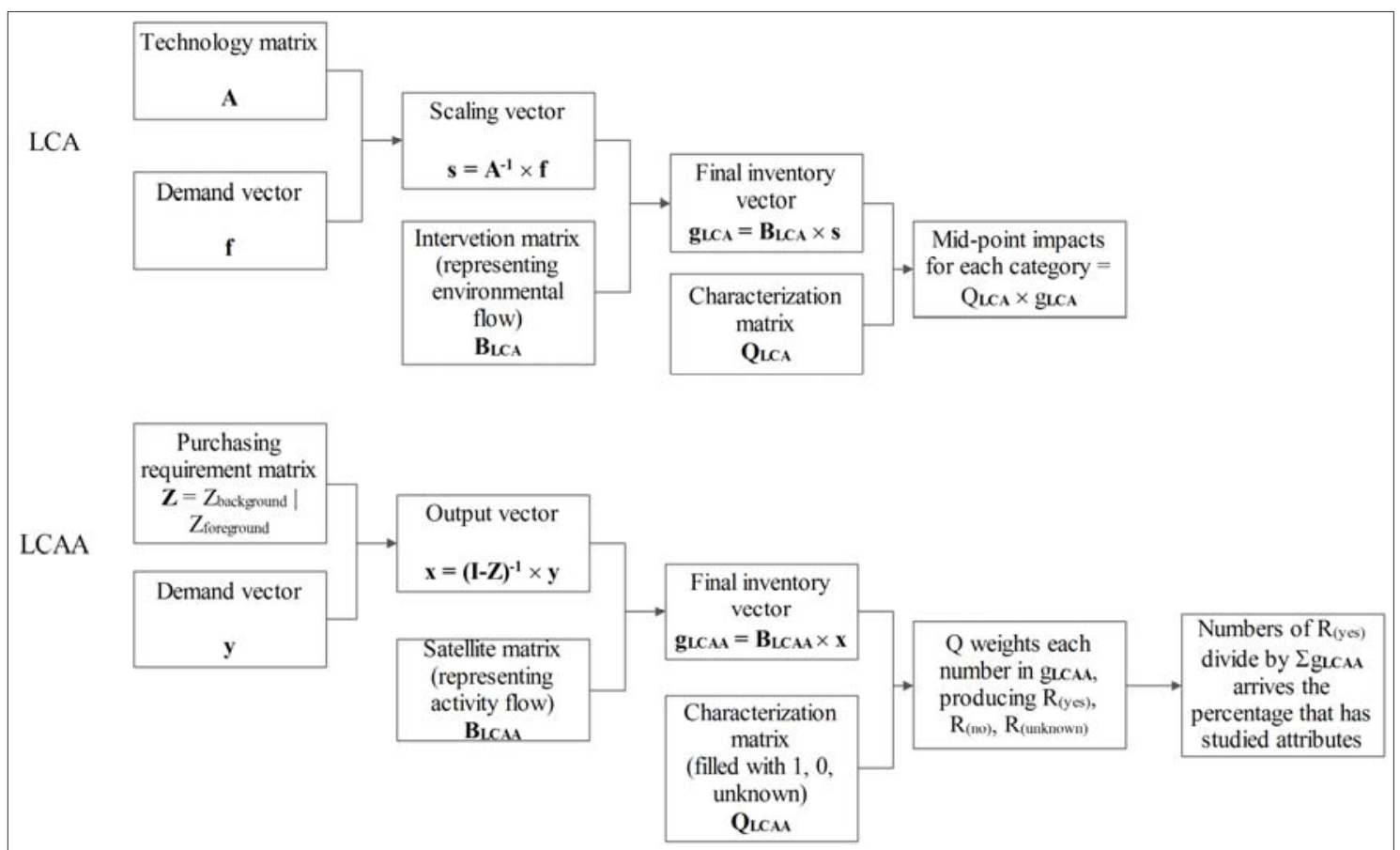

Notes: $Z_{\text {background }}$ : economy-wide purchasing data table; $Z_{\text {foreground }}$ direct requirement purchasing table (from the studied company and its first-tier suppliers purchasing data); $Z$ : combined matrix by $Z_{\text {background }}$ and $Z_{\text {foreground; }}$; $\mathrm{y}$ : final demand vector, representing the functional unit, in monetary value for LCAA (e.g., \$100 of products); I: identical matrix; $\mathrm{B}_{\mathrm{LCAA}}$ : satellite matrix, similar to the environmental intervention matrix $\left(\mathrm{B}_{\mathrm{LCA}}\right)$ in LCA. Unlike in LCA, where the environmental intervention matrix is available, in LCAA, $\mathrm{B}_{\mathrm{LCAA}}$ has to be constructed by practitioners themselves, depending on what attributes are to be studied. For example, if one wants to measure how many labor hours are local along the supply chain, $\mathrm{B}_{\mathrm{LCAA}}$ is collected as labor hours per $\$$ output of each sector in $Z$. If one wants to measure the percentage of forested acres in the supply chain that are FSC certified, $\mathrm{B}_{\mathrm{LCAA}}$ is

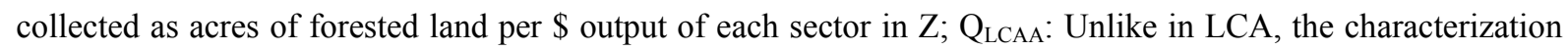
factors are readily available, in LCAA, $\mathrm{Q}_{\mathrm{LCAA}}$ has to be constructed by practitioners themselves, representing whether or not the company/sector satisfies the studied attributes. For example, if one wants to measure how many labor hours are local along the supply chain, then $\mathrm{Q}_{\mathrm{LCAA}}$ is constructed as a vector filled by 1 (yes, the product is produced locally), 0 (no, the product is not produced locally) and unknown, which is used for $Z_{\text {background }}$ to ease data collection burdens. 


\section{Conflicts of Interest}

The authors declare no conflicts of interest.

\section{References}

1. O’Brien, M.; Doig, A.; Clift, R. Social and environmental life cycle assessment (SELCA). Int. J. Life Cycle Ass. 1996, 1, 231-237.

2. Benoît, C.; Norris, G.; Valdivia, S.; Ciroth, A.; Moberg, A.; Bos, U.; Prakash, S.; Ugaya, C.; Beck, T. The guidelines for social life cycle assessment of products: Just in time! Int. J. Life Cycle Ass. 2010, 15, 156-163.

3. Macombe, C.; Feschet, P.; Garrabé, M.; Loeillet, D. 2nd International Seminar in Social Life Cycle Assessment-Recent developments in assessing the social impacts of product life cycles. Int. J. Life Cycle Ass. 2011, 16, 940-943.

4. Cinelli, M.; Coles, S.; Jørgensen, A.; Zamagni, A.; Fernando, C.; Kirwan, K. Workshop on life cycle sustainability assessment: The state of the art and research needs-26 November 2012, Copenhagen, Denmark. Int. J. Life Cycle Ass. 2013, 18, 1421-1424.

5. Jørgensen, A.; Bocq, A.; Nazarkina, L.; Hauschild, M. Methodologies for social life cycle assessment. Int. J. Life Cycle Ass. 2008, 13, 96-103.

6. Parent, J.; Cucuzzella, C.; Revéret, J.-P. Impact assessment in SLCA: Sorting the sLCIA methods according to their outcomes. Int. J. Life Cycle Ass. 2010, 15, 164-171.

7. Benoît, C., Mazijn, B., Eds. Guidelines for Social Life Cycle Assessment of Products. Available online: http://www.unep.fr/shared/publications/pdf/DTIx1164xPA-guidelines_sLCA.pdf (accessed on 20 Febuary 2014).

8. Schmidt, I.; Meurer, M.; Saling, P.; Kicherer, A.; Reuter, W.; Gensch, C.-O. SEEbalance ${ }^{\circledR}$ : Managing Sustainability of Products and Processes with the Socio-Eco-Efficiency Analysis by BASF. Greener Manag. Int. 2005, 45, 79-94.

9. Hunkeler, D. Societal LCA Methodology and Case Study (12 pp). Int. J. Life Cycle Ass. 2006, 11, 371-382.

10. Vinyes, E.; Oliver-Solà, J.; Ugaya, C.; Rieradevall, J.; Gasol, C. Application of LCSA to used cooking oil waste management. Int. J. Life Cycle Ass. 2013, 18, 445-455.

11. Lagarde, V.; Macombe, C. Designing the social life cycle of products from the systematic competitive model. Int. J. Life Cycle Ass. 2013, 18, 172-184.

12. Hosseinijou, S.; Mansour, S.; Shirazi, M. Social life cycle assessment for material selection: A case study of building materials. Int. J. Life Cycle Ass. 2014, 19, 620-645.

13. Jørgensen, A.; Finkbeiner, M.; Jørgensen, M.; Hauschild, M. Defining the baseline in social life cycle assessment. Int. J. Life Cycle Ass. 2010, 15, 376-384.

14. Ekener-Petersen, E.; Finnveden, G. Potential hotspots identified by social LCA —Part 1: A case study of a laptop computer. Int. J. Life Cycle Ass. 2013, 18, 127-143.

15. Ciroth, A.; Franze, J. LCA of An Ecolabeled Notebook-Consideration of Social and Environmental Impacts Along the Entire Life Cycle; GreenDeltaTC: Berlin, Germany, 2011.

16. Reitinger, C.; Dumke, M.; Barosevcic, M.; Hillerbrand, R. A conceptual framework for impact assessment within SLCA. Int. J. Life Cycle Ass. 2011, 16, 380-388. 
17. Dreyer, L.; Hauschild, M.; Schierbeck, J. A framework for social life cycle impact assessment (10 pp). Int. J. Life Cycle Ass. 2006, 11, 88-97.

18. Andrews, E.; Lesage, P.; Benoît, C.; Parent, J.; Norris, G.; Revéret, J.-P. Life cycle attribute assessment. J. Ind. Ecol. 2009, 13, 565-578.

19. Dreyer, L.; Hauschild, M.; Schierbeck, J. Characterisation of social impacts in LCA. Part. 2: Implementation in six company case studies. Int. J. Life Cycle Ass. 2010, 15, 385-402.

20. Dreyer, L.; Hauschild, M.; Schierbeck, J. Characterisation of social impacts in LCA. Int. J. Life Cycle Ass. 2010, 15, 247-259.

21. Aparcana, S.; Salhofer, S. Application of a methodology for the social life cycle assessment of recycling systems in low income countries: Three Peruvian case studies. Int. J. Life Cycle Ass. 2013, 18, 1116-1128.

22. Aparcana, S.; Salhofer, S. Development of a social impact assessment methodology for recycling systems in low-income countries. Int. J. Life Cycle Ass. 2013, 18, 1106-1115.

23. Hsu, C.-W.; Wang, S.-W.; Hu, A. Development of a New Methodology for Impact Assessment of SLCA, in Re-engineering Manufacturing for Sustainability; Nee, A.Y.C., Song, B., Ong, S.-K., Eds.; Springer: Singapore, Singapore, 2013; pp. 469-473.

24. Franze, J.; Ciroth, A. A comparison of cut roses from Ecuador and the Netherlands. Int. J. Life Cycle Ass. 2011, 16, 366-379.

25. Foolmaun, R.; Ramjeeawon, T. Comparative life cycle assessment and social life cycle assessment of used polyethylene terephthalate (PET) bottles in Mauritius. Int. J. Life Cycle Ass. 2013, 18, 155-171.

26. Manik, Y.; Leahy, J.; Halog, A. Social life cycle assessment of palm oil biodiesel: A case study in Jambi Province of Indonesia. Int. J. Life Cycle Ass. 2013, 18, 1386-1392.

27. Hutchins, M.J.; Sutherland, J.W. An exploration of measures of social sustainability and their application to supply chain decisions. J. Clean. Prod. 2008, 16, 1688-1698.

28. Martínez-Blanco, J.; Lehmann, A.; Muñoz, P.; Antón, A.; Traverso, M.; Rieradevall, J.; Finkbeiner, M. Application challenges for the social LCA of fertilizers within Life Cycle Sustainability Assessment. J. Clean. Prod. 2014, 69, 34-48.

29. Weidema, B. The Integration of Economic and Social Aspects in Life Cycle Impact Assessment. Int. J. Life Cycle Ass. 2006, 11, 89-96.

30. Brent, A.; Labuschagne, C. Social indicators for sustainable project and technology life cycle management in the process industry (13 pp + 4). Int. J. Life Cycle Ass. 2006, 11, 3-15.

31. Norris, G. Social Impacts in Product Life Cycles-Towards Life Cycle Attribute Assessment. Int. J. Life Cycle Ass. 2006, 11, 97-104.

32. Feschet, P.; Macombe, C.; Garrabé, M.; Loeillet, D.; Saez, A.; Benhmad, F. Social impact assessment in LCA using the Preston pathway. Int. J. Life Cycle Ass. 2013, 18, 490-503.

33. Gauthier, C. Measuring corporate social and environmental performance: The extended life-cycle assessment. J. Bus. Ethics 2005, 59, 199-206.

34. Jørgensen, A. Social LCA—A way ahead? Int. J. Life Cycle Ass. 2013, 18, 296-299.

35. Norris, C.B.; Aulisio, D.; Norris, G.A. Working with the social hotspots database-Methodology and findings from 7 social scoping assessments. In Proccedings of the 19th CIRP International Conference on Life Cycle Engineering, Berkeley,CA, USA, 23-25 May 2012. 
36. Benoit-Norris, C.; Cavan, D.A.; Norris, G. Identifying social impacts in product supply chains: Overview and application of the social hotspot database. Sustainability 2012, 4, 1946-1965.

37. Swarr, T. Societal life cycle assessment-Could you repeat the question? Int. J. Life Cycle Ass. 2009, 14, 285-289.

38. Dreyer, L.; Hauschild, M. Scoping Must be Done in Accordance with the Goal Definition, also in Social LCA. Int. J. Life Cycle Ass. 2006, 11, 87.

39. Macombe, C.; Leskinen, P.; Feschet, P.; Antikainen, R. Social life cycle assessment of biodiesel production at three levels: A literature review and development needs. J. Clean. Prod. 2013, 52, 205-216.

40. Zamagni, A.; Amerighi, O.; Buttol, P. Strengths or bias in social LCA? Int. J. Life Cycle Ass. 2011, 16, 596-598.

41. Parent, J.; Cucuzzella, C.; Revéret, J.-P. Revisiting the role of LCA and SLCA in the transition towards sustainable production and consumption. Int. J. Life Cycle Ass. 2013, 18, 1642-1652.

42. Jørgensen, A.; Lai, L.H.; Hauschild, M. Assessing the validity of impact pathways for child labour and well-being in social life cycle assessment. Int. J. Life Cycle Ass. 2010, 15, 5-16.

43. Reitinger, C. Proposals for Social Impact Categories from a Philosophical Perspective. In Proceedings of International Seminar on Social LCA, Montpellier, France, 5-6 May 2011.

44. Hauschild, M.Z.; Dreyer, L.C.; Jørgensen, A. Assessing social impacts in a life cycle perspective-Lessons learned. CIRP Ann. Manuf. Techn. 2008, 57, 21-24.

45. Weidema, B. Social impact categories, indicators, characterisation and damage modelling. In Proccedings of the 29th Swiss LCA Discussion Forum, Lausanne, Switzerland, 15 June 2006.

46. Carlsson, M.; Eriksson, S.; Gottfries, N. Testing Theories of Job Creation: Does Supply Create Its Own Demand? Sveriges Riksbank Working Paper Series, No. 194; Econstor: Kiel, Germany, 2006.

47. Hakim, C. The social consequences of high unemployment. J. Soc. Policy 1982, 11, 433-467.

48. Grisez, G.; Boyle, J.; Finnis, J. Practical Principles, Moral Truth, and Ultimate Ends. Am. J. Jurisprud. 1987, 32, 99-151.

49. Alkire, S. Dimensions of Human Development. World Dev. 2002, 30, 181-205.

50. Alkire, S. Valuing Freedoms: Sen's Capability Approach and Poverty Reduction; Oxford University Press: Oxford, UK, 2005.

51. Heijungs, R.; Suh, S. The Computational Structure of Life Cycle Assessment; Springer: Berlin, Germany, 2002; pp. 11-22.

52. GRI. Global Reporting Initiative G4 Sustainability Reporting Guidelines. Available online: https:/www.globalreporting.org/resourcelibrary/GRIG4-Part1-Reporting-Principles-and-StandardDisclosures.pdf (accessed on 20 Febuary 2014).

53. Lehmann, A.; Zschieschang, E.; Traverso, M.; Finkbeiner, M.; Schebek, L. Social aspects for sustainability assessment of technologies-Challenges for social life cycle assessment (SLCA). Int. J. Life Cycle Ass. 2013, 18, 1581-1592.

54. Jørgensen, A.; Dreyer, L.; Wangel, A. Addressing the effect of social life cycle assessments. Int. J. Life Cycle Ass. 2012, 17, 828-839.

55. Jørgensen, A.; Dreyer, L.; Wangel. A. The effect of three different SLCA methods. In Proccedings of the International Seminar on Social LCA, Montpellier, France, 5-6 May 2011.

56. Zamagni, A. Life cycle sustainability assessment. Int. J. Life Cycle Ass. 2012, 17, 373-376. 
57. Valdivia, S., Ugaya, C., Sonnemann, G., Hildenbrand, J., Eds. Towards a Life Cycle Sustainability Assessment: Making Informed Choices on Products; UNEP/SETAC Life Cycle Initiative: Paris, France, 2011.

58. Finkbeiner, M.; Schau, E.; Lehmann, A.; Traverso, M. Towards Life Cycle Sustainability Assessment. Sustainability 2010, 2, 3309-3322.

59. Kloepffer, W. Life cycle sustainability assessment of products. Int. J. Life Cycle Ass. 2008, 13, 89-95.

60. PROSUITE. PROSUITE: PROspective SUstaInability Assessment of TEchnologies. Available online: http://www.prosuite.org/web/guest/home;jsessionid=30BB607DE3ACFB15A8D13A06FBD5C6EC (accessed on 20 Febuary 2014).

61. Laquerre, M.; Brodeur, C. The use of SLCA in the development of an extended producer responsibility policy: Testing end of life scenarios for computer products in Québec. In Proccedings of the International Seminar on Social LCA, Montpellier, France, 5-6 May 2011.

(C) 2014 by the authors; licensee MDPI, Basel, Switzerland. This article is an open access article distributed under the terms and conditions of the Creative Commons Attribution license (http://creativecommons.org/licenses/by/3.0/). 